\title{
Electrical Conductivities and Interactions in Binary Mixtures of Imidazolium-Based Ionic Liquids with Acetonitrile and Dimethyl Sulfoxide
}

\author{
OANA CIOCIRLAN ${ }^{1}$, AMALIA STEFANIU ${ }^{2 *}$ \\ ${ }^{1}$ University Politehnica of Bucharest, Faculty of Applied Chemistry and Materials Science, 132 Calea Grivitei, 010737, \\ Bucharest, Romania \\ ${ }^{2}$ National Institute for Chemical - Pharmaceutical Research and Development - ICCF, 112, Vitan Av., 031299, Bucharest, \\ Romania
}

This paper reports experimental electrical conductivities data of eight binary systems of four ionic liquids: 1butyl-3-methylimidazolium tetrafluoroborate, [Bmim][BF4], 1-hexyl-3-methylimidazolium tetrafluoroborate, [Hmim][BF4], 1-butyl-3-methylimidazolium hexafluorophosphate, [Bmim][PF6] and 1-butyl-2,3-dimethylimidazolium tetrafluoroborate, [Bmmim][BF4] with the organic solvents dimethyl sulfoxide (DMSO) and acetonitrile $(A C N)$ at atmospheric pressure and temperatures from 298.15 to $328.15 \mathrm{~K}$. It was found that conductivities in the investigated ionic liquids follow the order: [Bmim][BF4] > [Bmim][PF6] > [Bmmim][BF4] $>$ [Hmim][BF4]. Experimental results demonstrate that the binary mixtures possess higher electrical conductivity compared with pure components. Electrical conductivity data were correlated using Casteel-Amis and Arrhenius equations. The molar conductivity was derived from experimental data and fitted to Walden rule. The influence of the cation structure and anion type on the conductivity was discussed, which help understanding the intermolecular interactions in the binary systems. A deeper understanding of the transport behavior of ILs is given by means of density functional theory calculations (DFT)

Keywords: imidazolium-based ionic liquids, DMSO, acetonitrile, electrical conductivity, DFT

Ionic liquids (ILs), also known as molten salts, represent a new class of solvents with potential to replace volatile organic solvents within the chemical and related industries. Their strengths come from their negligible volatility, nonflammability, excellent thermal and chemical stability, high solubility, high ionic conductivity, and wide electrochemical potential window. These properties recommend them as electrolytic materials in electrochemical devices [1], solvents/adsorbents for capture of greenhouse gases like $\mathrm{CO}_{2}$ [2], solvents in catalysis [3] or in synthesis of metallic oxides [4], etc.

To explore these numerous applications, one needs to know their most important physico-chemical properties. Among them, transport properties such as electrical conductivity and dynamic viscosity are important in chemical and engineering processes, especially electrochemical field. The drawbacks of ILs are the high viscosities and moderate conductivities, that can be adjusted by mixing with molecular liquids. This was found to cause a significant decrease of viscosity and a significant enhancement in the electrical conductivity, especially at some composition of the mixtures [5-14].

The organic solvents used in this study are polar substances which belong to the class 2 (ACN) and 3 (DMSO) of solvents, according to the classification used in pharmaceutical industry; ACN was chosen due to its wide applicability in electrochemistry and physical chemistry of electrolyte solutions [6-9] and DMSO, for its extensive use in many chemical processes, biology and medicine $[14,15]$. In this study we selected the commonly investigated ILs with tetrafluoroborate $\left(\mathrm{BF}_{4}^{-}\right)$and hexafluorophosphate $\left(\mathrm{PF}_{6}{ }^{-}\right)$anions and imidazolium cation, due to the relatively lower viscosities, higher ionic conductivities and large potential windows associated with these ions.

During our systematic research on the thermodynamic and transport properties of the binary and ternary systems [16,17] we also studied mixtures with ionic liquids [18-22]. In the present work we determined the electrical conductivities of four imidazolium based ionic liquids: [Bmim][BF4], [Hmim][BF4], [Bmim][PF6] and [Bmmim][BF4] and their binary mixtures with ACN and DMSO, respectively, at temperatures between $298.15 \mathrm{~K}$ and $328.15 \mathrm{~K}$ and atmospheric pressure $(\mathrm{P}=0.1 \mathrm{MPa})$. Electrical conductivity data for the binary systems $[\mathrm{Bmim}][\mathrm{BF} 4]$ with $\mathrm{ACN}$ and DMSO, respectively, at $298.15 \mathrm{~K}$ are reported elsewhere [22]. We investigated the effects of temperature on electrical

*email:astefaniu@gmail.com 
Rev. Chim. $71 \bullet$ no. $2 \bullet 2020 \bullet$ https://revistadechimie.ro

conductivity by the Arrhenius equation. The concentration dependence of the electrical conductivity of the mixtures was fitted by the empirical Casteel-Amis equation. Conductivity data, coupled with information on viscosity, are discussed in terms of Walden's rule. The main goals of the study are to report new electrical conductivity data for eight binary systems, and to discuss the influence of different parameters on the conductivity. Thus, we consider the structure, size and shape of constitutive ions of ionic liquids, but also the interactions between ILs and organic solvents.

In order to obtain a deeper inside molecular view of ionic pairs, a series of quantum chemical descriptors and structural features were obtained with DFT calculations and used to characterize the ionic liquids in terms of kinetic stability and chemical reactivity, trying to correlate them with special properties of ILs - low ionic conductivity and high viscosity. There are studies with DFT calculations in the literature [23] which are conducted in order to predict ILs ion volumes, masses, moments of inertia and interaction energies, used to construct models for computing conductivity.

\section{Experimental part}

Materials. 1-butyl-3-methylimidazolium tetrafluoroborate (> 99.9 mass \%) from Merck, 1-hexyl-3-methylimidazolium tetrafluoroborate (> 99.5 mass \%) from Merck, 1-butyl-3-methylimidazolium hexafluorophosphate, 1-butyl-2,3dimethylimidazolium tetrafluoroborate ([Bmmim][BF4] (> 99.8 mass \%) from Sigma Aldrich, DMSO (> 99.9 mass \%) and ACN (> 99.5 mass \%), from Merck were used. The organic solvents were dried and stored over 3A molecular sieves. For ionic liquids which are hygroscopic, we dried them into a Schlenk tube under vacuum at $333 \mathrm{~K}$ for $11 \mathrm{~h}$, afterwards sample preparation was performed under nitrogen to minimize contact with the atmosphere. For loading the samples into the apparatus syringes equipped with a Luer Lock valve were used.

Apparatus and Procedure. The binary mixtures were prepared gravimetrically with a HR-120 (A\&D Japan) electronic balance with a precision of $\pm 10^{-4} \mathrm{~g}$. The experimental uncertainty in mole fractions was estimated to be less than \pm 0.0002 .

Measurement of electrical conductivity $(\lambda)$. The conductivity measurements were carried out with a Cobra 3 ChemUnit (PHYWE) conductivity meter, using a specially designed cell (electrode LTG 1/24) suitable for low conductivity measurement. Before any measurement the conductivity cell was calibrated with a standard $\mathrm{KCl}$ solution $\left(\lambda=1.4 \mathrm{mS} \cdot \mathrm{cm}^{-}\right.$ $\left.{ }^{1}\right)$. The conductivity cells were filled with samples and sealed with parafilm, then transferred to the thermostat bath. The temperature was kept constant within $\pm 0.05 \mathrm{~K}$ with an external oil bath. All measurements were done by means of a static isothermal method, thus we waited for about $20 \mathrm{~min}$ with the sample at constant temperature before any single measurement was

performed. The uncertainty of the conductivity measurements was estimated to be $\pm 2 \%$.

\section{Computational details}

Density functional theory (DFT) calculations were carried out on the optimized geometries, as lowest energy structures of ionic pairs, using Becke's Three Parameter Hybrid Functional using the Lee-Yang-Parr correlation functional theory (B3LYP) [24] and basis set 6-31+G*[25,26], with Spartan'18 Parallel Suite software package from Wavefunction, Inc., Irvine, CA, U.S.A. [26]. The quantum chemical calculations were performed in vacuum, for equilibrium geometry at ground state.

\section{Results and discussions}

The experimental electrical conductivity data for the binary mixtures of [Bmim][BF4], [Bmim][PF6], [Hmim][BF4], and $[\mathrm{Bmmim}][\mathrm{BF} 4]$ with DMSO and $\mathrm{ACN}$, respectively, at temperatures of $(298.15,308.15,318.15$ and 328.15$) \mathrm{K}$ over the entire composition range and atmospheric pressure $(\mathrm{P}=0.1 \mathrm{MPa})$ are listed in Table 1.

Table 1

ELECTRICAL CONDUCTIVITY DATA, $\lambda\left(\mathrm{mS}^{\cdot} \mathrm{cm}^{-1}\right)$ FOR THE BINARY SYSTEMS OF IONIC LIQUIDS [Bmim][BF4], [Bmim][PF6], $\left[\mathrm{Hmim}_{[}\right]\left[\mathrm{BF}_{4}\right]$ AND $\left[\mathrm{Bmmim}_{[}\left[\mathrm{BF}_{4}\right]\right.$ WITH ACETONITRILE AND DIMETHYL SULFOXIDE AT DIFFERENT TEMPERATURES

\begin{tabular}{|c|c|c|c|c|c|c|c|c|c|}
\hline$X_{I L}$ & $298.15 \mathrm{~K}$ & $308.15 \mathrm{~K}$ & $318.15 \mathrm{~K}$ & $328.15 \mathrm{~K}$ & $X_{I I}$ & $298.15 \mathrm{~K}$ & $308.15 \mathrm{~K}$ & $318.15 \mathrm{~K}$ & $328.15 \mathrm{~K}$ \\
\hline \multicolumn{5}{|c|}{$\left[\mathrm{Bmim}^{2}\right]\left[\mathrm{BF}_{4}\right]+\mathrm{ACN}$} & \multicolumn{5}{|c|}{$[\mathrm{Bmim}]\left[\mathrm{BF}_{4}\right]+\mathrm{DMSO}$} \\
\hline 0.1059 & $12.50^{*}$ & 13.99 & 15.48 & 16.97 & 0.0722 & $9.74^{\mp}$ & 11.26 & 12.77 & 14.29 \\
\hline 0.2213 & $11.64^{*-}$ & 13.13 & 14.60 & 16.08 & 0.1764 & $10.32^{*}$ & 11.88 & 13.43 & 14.99 \\
\hline 0.3008 & $10.80^{*}$ & 12.56 & 14.31 & 16.07 & 0.2145 & $10.16^{\star-}$ & 11.83 & 13.51 & 15.18 \\
\hline 0.3894 & $7.82^{*}$ & 9.54 & 11.27 & 13.00 & 0.3225 & $8.31^{=}$ & 10.25 & 12.20 & 14.14 \\
\hline 0.4432 & $7.33^{*}$ & 9.07 & 10.80 & 12.54 & 0.4189 & $6.72^{x^{-}}$ & 8.81 & 10.90 & 12.99 \\
\hline 0.6178 & $5.09^{x}$ & 6.64 & 8.19 & 9.73 & 0.607 & $4.36^{*}$ & 6.30 & 8.24 & 10.18 \\
\hline
\end{tabular}


Rev. Chim. $\$ 1 \downarrow$ no. $2 \downarrow 2020 \bullet$ https://revistadechimie.ro

\begin{tabular}{|c|c|c|c|c|c|c|c|c|c|}
\hline & & & & & & & & & \\
\hline 0.7111 & $3.74^{*}$ & 5.02 & 6.31 & 7.60 & 0.6557 & $3.52^{*}$ & 5.29 & 7.05 & 8.82 \\
\hline 0.8146 & $3.38^{\star}$ & 4.36 & 5.34 & 6.33 & 0.8283 & $2.84^{=}$ & 4.28 & 5.71 & 7.15 \\
\hline 1 & $2.43^{k^{-}}$ & 3.16 & 4.07 & $5.10^{-}$ & & & & & \\
\hline Ref [11] & 1.94 & & & & & & & & \\
\hline Ref [27] & & 3.64 & 5.42 & 7.83 & & & & & \\
\hline \multicolumn{5}{|c|}{$[\mathrm{Bmim}]\left[\mathrm{PF}_{6}\right]+\mathrm{ACN}$} & \multicolumn{5}{|c|}{$[\mathrm{Bmim}]\left[\mathrm{PF}_{6}\right]+\mathrm{DMSO}$} \\
\hline 0.0989 & 24.32 & 26.10 & 27.88 & 29.66 & 0.1241 & 9.22 & 10.85 & 12.48 & 14.11 \\
\hline 0.2442 & 14.00 & 15.87 & 17.73 & 19.60 & 0.2181 & 8.32 & 10.27 & 12.22 & 14.16 \\
\hline 0.3150 & 10.44 & 12.13 & 13.81 & 15.50 & 0.3049 & 6.28 & $8.70^{-}$ & 11.13 & 13.55 \\
\hline 0.4201 & 7.96 & 9.07 & 10.17 & 11.28 & 0.3865 & 5.21 & 7.67 & 10.12 & 12.58 \\
\hline 0.4940 & 7.17 & 7.91 & 8.64 & 9.37 & 0.4870 & 3.20 & 5.61 & 8.02 & 10.43 \\
\hline 0.5854 & 4.67 & 5.38 & 6.08 & 6.78 & 0.6482 & 2.19 & 3.79 & 5.39 & 6.99 \\
\hline 0.6274 & 3.49 & 4.32 & 5.14 & 5.97 & 0.7200 & 1.88 & 3.25 & 4.61 & 5.98 \\
\hline 0.8022 & 2.19 & 2.83 & 3.47 & 4.11 & 0.8519 & 1.48 & 2.42 & 3.36 & 4.30 \\
\hline 0.8832 & 2.41 & 3.10 & 3.78 & 4.46 & 0.9350 & 1.28 & 2.13 & 2.98 & 3.83 \\
\hline 1 & 1.19 & 1.90 & 2.62 & 3.33 & 1 & 1.19 & $1.90^{\circ}$ & 2.62 & 3.33 \\
\hline Ref $[10]$ & 1.47 & & & & & & & & \\
\hline $\operatorname{Ref}[11]$ & 1.57 & & & & & & & & \\
\hline Ref [27] & & 1.49 & 2.45 & 3.83 & & & & & \\
\hline \multicolumn{5}{|c|}{$[\mathrm{Hmim}]\left[\mathrm{BF}_{4}\right]+\mathrm{ACN}$} & \multicolumn{5}{|c|}{$[\mathrm{Hmim}]\left[\mathrm{BF}_{4}\right]+\mathrm{DMSO}$} \\
\hline 0.1040 & 9.80 & 11.82 & 13.84 & 15.86 & 0.1160 & 8.21 & 9.91 & 11.60 & 13.29 \\
\hline 0.2948 & 6.42 & 8.94 & 11.45 & 13.97 & 0.2831 & 6.67 & 8.71 & 10.75 & 12.79 \\
\hline 0.4066 & 4.45 & 6.26 & 8.07 & 9.88 & 0.3857 & 4.75 & 7.06 & 9.37 & 11.68 \\
\hline 0.5697 & 3.57 & 4.83 & 6.09 & 7.35 & 0.5036 & 3.26 & 5.35 & 7.44 & 9.53 \\
\hline 0.6626 & 2.38 & 3.40 & 4.41 & 5.43 & 0.6702 & 2.11 & 3.80 & 5.49 & 7.19 \\
\hline 0.8329 & 1.70 & 2.52 & 3.34 & 4.16 & 0.7883 & 1.65 & 3.00 & 4.35 & 5.70 \\
\hline 1 & 0.61 & 1.07 & 1.60 & 2.16 & 1 & 0.61 & 1.07 & 1.60 & 2.16 \\
\hline Ref [28] & 1.229 & 1.49 & 2.45 & 4.83 & & & & & \\
\hline Ref [29] & & 0.053 & 0.133 & 0.295 & & & & & \\
\hline \multicolumn{5}{|c|}{$[\mathrm{Bmmim}]\left[\mathrm{BF}_{4}\right]+\mathrm{ACN}$} & \multicolumn{5}{|c|}{$[\mathrm{Bmmim}]\left[\mathrm{BF}_{4}\right]+\mathrm{DMSO}$} \\
\hline 0.1118 & 13.21 & 15.26 & 17.31 & 19.37 & 0.1380 & 8.80 & 10.97 & 13.13 & 15.29 \\
\hline 0.2247 & 10.81 & 12.00 & 13.19 & 14.37 & 0.2292 & 7.60 & $9.78^{-}$ & 11.96 & 14.15 \\
\hline 0.3464 & 6.30 & 7.63 & 8.95 & 10.28 & 0.3151 & 6.47 & 8.68 & 10.89 & 13.10 \\
\hline 0.3784 & 5.23 & 6.49 & 7.75 & 9.01 & 0.4079 & 4.44 & 6.59 & 8.74 & 10.89 \\
\hline 0.5515 & 2.65 & 3.45 & 4.25 & 5.06 & 0.5334 & 2.75 & 4.30 & 5.84 & 7.39 \\
\hline 0.6660 & 1.91 & 2.43 & 2.96 & 3.49 & 0.6374 & 2.00 & 3.16 & 4.31 & 5.47 \\
\hline 0.7581 & $1.65^{-}$ & 1.95 & 2.25 & 2.55 & 0.7004 & 1.59 & 2.57 & 3.56 & 4.54 \\
\hline 0.8423 & 1.17 & 1.57 & 1.97 & 2.37 & 0.8785 & 1.18 & 1.76 & 2.35 & 2.93 \\
\hline 1 & 0.63 & 1.16 & 1.69 & 2.22 & 1 & 0.63 & 1.16 & 1.69 & 2.22 \\
\hline Ref [30] & & 1.06 & 1.937 & 3.27 & & & & & \\
\hline
\end{tabular}

${ }^{*}$ ) Data published according with ref [22]

At all temperatures the electrical conductivity of the neat ILs varies in the order: $[\mathrm{Bmim}][\mathrm{BF} 4]>[\mathrm{Bmim}][\mathrm{PF} 6]$ $>[\mathrm{Bmmim}][\mathrm{BF} 4]>[\mathrm{Hmim}][\mathrm{BF} 4]$ as other authors report $[10,12]$. As expected, this order is almost opposite to that observed for viscosity, that means: $[\mathrm{Bmmim}][\mathrm{BF} 4]>[\mathrm{Bmim}][\mathrm{PF} 6]>[\mathrm{Hmim}][\mathrm{BF} 4]>[\mathrm{Bmim}][\mathrm{BF} 4][11,19,21,22]$. Conductivities of neat ILs determined by us are, in general, smaller than those from literature, with relative deviations greater than $2 \%$ (going up to $100 \%$ for [Hmim][BF4]) for all systems and temperatures $[8,10,11,27-30]$.

Ion-pair formation and movement of ions influence the electrical (ionic) conductivity of the IL. For ILs with the same cation the conductivity is a function of mobility and size of the anion. Indeed, for the ionic liquid [Bmim][BF4], which has smaller anion than [Bmim][PF6], a higher conductivity (higher mobility) was observed at all investigated temperatures. Decrease of the electrical conductivity for ILs with longer alkyl chain length is in accordance with the fact that electrical conductivity largely depends on the viscosity of the system [31]. Moreover, the conductivity of $[\mathrm{Bmim}][\mathrm{BF} 4]$ is higher than of [Bmmim] [BF4], coupled with higher viscosity of last one because of the poorer mobility of the tri-substituted cation. This can be explained by the restriction of the butyl chain free rotation due to the steric bulk caused by the methyl group at the 2-position of the cation and also to the energetic preference of the anion to lie above or below the imidazolium ring rather than in front of it [32].

The temperature dependence of the conductivity of the neat ionic liquids was observed to follow the behavior predicted by the Arrhenius equation: 


$$
\ln \lambda=\ln A-\frac{E_{a}}{R T}
$$

Rev. Chim. $\bullet 11$ no. $2 \bullet 2020 \bullet$ https://revistadechimie.ro

where $\lambda$ is the electrical conductivity, $E_{a}$ is the activation energy for ion transportation by migration, $A$ is the preexponential factor (or frequency factor), $R$ is the universal gas constant. Figure 1 shows this behavior and Table 2 presents the values of parameters, including correlation coefficient $\mathrm{R}^{2}$ and standard deviation. The standard deviation of the fit was found in the range of $0.015-0.127 \mathrm{mS} \cdot \mathrm{cm}^{-1}$.

Table 2

VALUES OF $E_{d} / R, \ln A, R^{2}$ AND $\sigma$ DERIVED FROM ARRHENIUS EQUATION OF PURE IONIC LIQUIDS (PLOTS IN FIGURE 1)

\begin{tabular}{|l|c|c|c|c|}
\hline \multicolumn{4}{|c|}{ OF PURE IONIC LIQUIDS (PLOTS IN FIGURE 1) } \\
\hline Ionic liquids & $\ln \left(\mathrm{A}, \mathrm{mS} \cdot \mathrm{cm}^{-1}\right)$ & $E_{\sigma} / R$ & $R^{2}$ & $\sigma\left(\mathrm{mS} \cdot \mathrm{cm}^{-1}\right)$ \\
\hline$[$ Bmim][BF4] & 8.995 & 2416.7 & 0.999 & 0.015 \\
\hline$[$ Bmim][PF6] & 10.689 & 3106.7 & 0.985 & 0.127 \\
\hline$[$ Bmmim][BF4] & 11.936 & 3647.5 & 0.976 & 0.114 \\
\hline$[$ Hmim][BF4] & 12.314 & 3782.5 & 0.988 & 0.082 \\
\hline
\end{tabular}

[Bmim][BF4]; $\mathbf{\square},[\mathrm{Bmim}][\mathrm{PF} 6] ; \boldsymbol{\Delta}$,

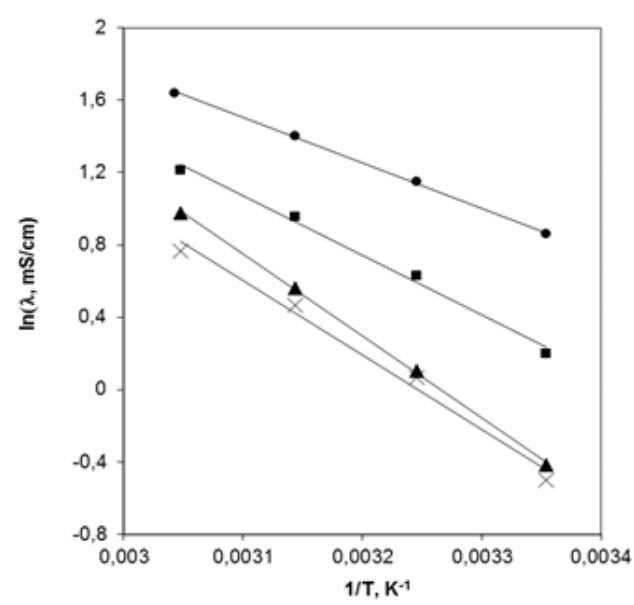

[Bmmim][BF4]; $\times$, [Hmim][BF4]; Solid lines represent the fit of data to Arrhenius eq.

The obtained activation energies (Table 2) increase in the order: $[\mathrm{Bmim}][\mathrm{BF} 4]<[\mathrm{Bmim}][\mathrm{PF} 6]<[\mathrm{Hmim}][\mathrm{BF} 4]<$ [Bmmim][BF4], reflecting the above statements. In general, a more precise equation like Vogel- Fulcher-Tamman equation is used for temperature behavior of transport properties, especially on larger temperature intervals, including lower temperatures [7,33,34].

Molecular dynamics studies [35-37] have indicated that there is significant ionic association in neat ILs which leads to high viscosity, limited conductivity and other peculiar properties of these organic salts. Mixing ionic liquids with molecular solvents will reduce coulombic interactions and release free ions from their associations, leading to decreased viscosity and increased conductivity [13,38]. A fluid with a large dielectric constant (as is DMSO or ACN) can interact more effectively with both ions of the ionic liquid, disrupting its polar network and causing a decrease in the viscosity of the mixture. As a result, it increases the conductivity, thus facilitating mass transport $[14,38]$.

The dependence of electrical conductivity on IL mole fraction $\left(X_{I L}\right)$ follows the typical pattern of concentrated electrolyte solutions: after a rapid initial rise at low $X_{I L}$ due to the increasing number of charge carriers, conductivity exhibits a pronounced maximum at around $X_{I L} \approx 0.1$ to 0.2 (depending on the mixture) due to the counterbalancing effect of the rapidly rising viscosity on ion mobility $[9,10,39]$. In fact, the studies from literature demonstrate that ionic conductivity maximum occurs at compositions where the number of ion pairs, the so called "contact ion pairs" starts to exceed the number of free ions, or when ions come into contact, leading to a rapid growth of viscosity [6,9].

To reproduce such concentration dependence, the empirical Casteel-Amis equation is widely used [40]. Generally, data fitting is done on the molality scale, and the obtained parameters are the maximum conductivity, $\lambda_{\max }$, the corresponding 
concentration, $X_{\max }$, and shape parameters, $a$ and $b$. For the present systems, the Casteel-Amis equation can be reasonably applied to the mole fraction scale, that is:

Rev. Chim. $71 \bullet$ no. $2 \downarrow 2020 \bullet$ https://revistadechimie.ro

$$
\lambda=\lambda_{\max }\left(\frac{X_{I L}}{X_{\max }}\right)^{a} \exp \left(b\left(X_{I L}-X_{\max }\right)^{2}-a \frac{X_{I L}-X_{\max }}{X_{\max }}\right)
$$

where $X_{\max }$ is the IL mole fraction at $\lambda_{\max }$.

The fitted parameters are summarized in Table 3, together with the corresponding standard deviations, $\sigma$, defined as follows:

$$
\left.\sigma=\left[\sum_{i=1}^{n}\left(\lambda_{\exp }-\lambda_{\text {calc }}\right)\right)^{2} /(n-m)\right]^{0.5}
$$

where $n$ is the number of experimental data and $m$ is the number of parameters.

\section{Table 3}

THE BEST FITTING PARAMETERS AND STANDARD DEVIATIONS FOR THE EQUATION CASTEEL-AMIS USED TO CORRELATE CONDUCTIVITY DATA OF THE MIXTURES 


\begin{tabular}{|c|c|c|c|c|c|}
\hline$T, \mathrm{~K}$ & $a$ & b & $\lambda_{\max }\left(\mathrm{mS} \cdot \mathrm{cm}^{-1}\right)$ & $X_{\max }$ & $\sigma\left(\mathrm{mS} \cdot \mathrm{cm}^{-1}\right)$ \\
\hline \multicolumn{6}{|c|}{$[\mathrm{Bmim}][\mathrm{BF} 4]+\mathrm{DMSO}$} \\
\hline 298.15 & 0.688 & 1.884 & 10.8 & 0.137 & 0.276 \\
\hline 308.15 & 0.472 & 0.764 & 12.2 & 0.144 & 0.290 \\
\hline 318.15 & 0.329 & 0.001 & 13.7 & 0.153 & 0.323 \\
\hline 328.15 & 0.230 & -0.543 & 15.2 & 0.166 & 0.374 \\
\hline \multicolumn{6}{|c|}{$[\mathrm{Bmim}][\mathrm{BF} 4]+\mathrm{ACN}$} \\
\hline 298.15 & 0.724 & 1.756 & 12.8 & 0.141 & 0.347 \\
\hline 308.15 & 0.562 & 1.089 & 14.2 & 0.142 & 0.37 \\
\hline 318.15 & 0.450 & 0.599 & 15.7 & 0.143 & 0.421 \\
\hline 328.15 & 0.375 & 0.249 & 17.2 & 0.146 & 0.479 \\
\hline \multicolumn{6}{|c|}{$[\mathrm{Bmim}][\mathrm{PF} 6]+\mathrm{DMSO}$} \\
\hline 298.15 & 1.164 & 3.887 & 9.3 & 0.139 & 0.237 \\
\hline 308.15 & 0.739 & 1.475 & 10.9 & 0.148 & 0.241 \\
\hline 318.15 & 0.598 & 0.376 & 12.7 & 1.167 & 0.303 \\
\hline 328.15 & 0.550 & -0.221 & 14.6 & 0.191 & 0.403 \\
\hline \multicolumn{6}{|c|}{$[\mathrm{Bmim}][\mathrm{PF} 6]+\mathrm{ACN}$} \\
\hline 298.15 & 0.366 & 2.261 & 24.7 & 0.060 & 0.758 \\
\hline 308.15 & 0.232 & 1.808 & 27.5 & 0.046 & 0.658 \\
\hline 318.15 & 0.408 & 2.477 & 28.2 & 0.069 & 0.508 \\
\hline 328.15 & 0.454 & 2.673 & 29.9 & 0.075 & 0.437 \\
\hline \multicolumn{6}{|c|}{$[\mathrm{Hmim}][\mathrm{BF} 4]+\mathrm{DMSO}$} \\
\hline 298.15 & 0.882 & 1.861 & 8.3 & 0.140 & 0.273 \\
\hline 308.15 & 0.284 & -0.731 & 9.9 & 0.124 & 0.375 \\
\hline 318.15 & 0.029 & -1.970 & 11.6 & 0.095 & 0.462 \\
\hline 328.15 & -0.048 & -2.494 & 13.3 & 0.101 & 0.442 \\
\hline \multicolumn{6}{|c|}{$[\mathrm{Hmim}][\mathrm{BF} 4]+\mathrm{ACN}$} \\
\hline 298.15 & 1.003 & 3.206 & 10.2 & 0.131 & 0.645 \\
\hline 308.15 & 0.773 & 1.878 & 12.2 & 0.134 & 0.440 \\
\hline 318.15 & 0.689 & 1.249 & 14.3 & 0.139 & 0.400 \\
\hline 328.15 & 0.644 & 0.860 & 16.4 & 0.145 & 0.516 \\
\hline \multicolumn{6}{|c|}{ [Bmmim] $[\mathrm{BF} 4]+$ DMSO } \\
\hline 298.15 & 1.062 & 2.340 & 8.8 & 0.145 & 0.262 \\
\hline 308.15 & 0.844 & 1.273 & 10.9 & 0.150 & 0.300 \\
\hline 318.15 & 0.752 & 0.719 & 13.1 & 0.157 & 0.365 \\
\hline 328.15 & 0.708 & 0.389 & 15.3 & 0.165 & 0.451 \\
\hline \multicolumn{6}{|c|}{$[\mathrm{Bmmim}][\mathrm{BF} 4]+\mathrm{ACN}$} \\
\hline 298.15 & 1.347 & 5.068 & 13.3 & 0.126 & 0.229 \\
\hline 308.15 & 0.955 & 3.707 & 15.3 & 0.113 & 0.080 \\
\hline 318.15 & 0.694 & 2.791 & 17.4 & 0.099 & 0.146 \\
\hline 328.15 & 0.510 & 2.141 & 19.7 & 0.086 & 0.321 \\
\hline
\end{tabular}

Rev. Chim. $71 \downarrow$ no. $2 \downarrow 2020 \downarrow$ https://revistadechimie.ro

Generally, the four-parameter description of electrical conductivity as a function of IL mole fraction with Eq. 2 is good, with $\sigma<0.5 \mathrm{mS} \cdot \mathrm{cm}^{-1}$ for most systems at all temperatures, except for [Bmim][PF6] + ACN and [Hmim] [BF4] + ACN systems, where $\sigma$ values are bigger than 0.5 .

The electrical conductivities for the eight binary mixtures of [Bmim][BF4], [Bmim][PF6], [Hmim][BF4], [Bmmim][BF4] with DMSO and ACN, respectively, at the investigated temperatures were depicted in Figures 2 a-h. From these Figures it can be observed that the conductivity maximum in each mixture increases with increasing temperature and moves, generally, towards higher concentrations as temperature increases. It is noticed that the conductivities for the systems with ACN are higher than those with DMSO and the order of variation in the systems with DMSO follows an approximative order as in the neat ILs, while for the systems with acetonitrile, the order of variation is somewhat reversed. 


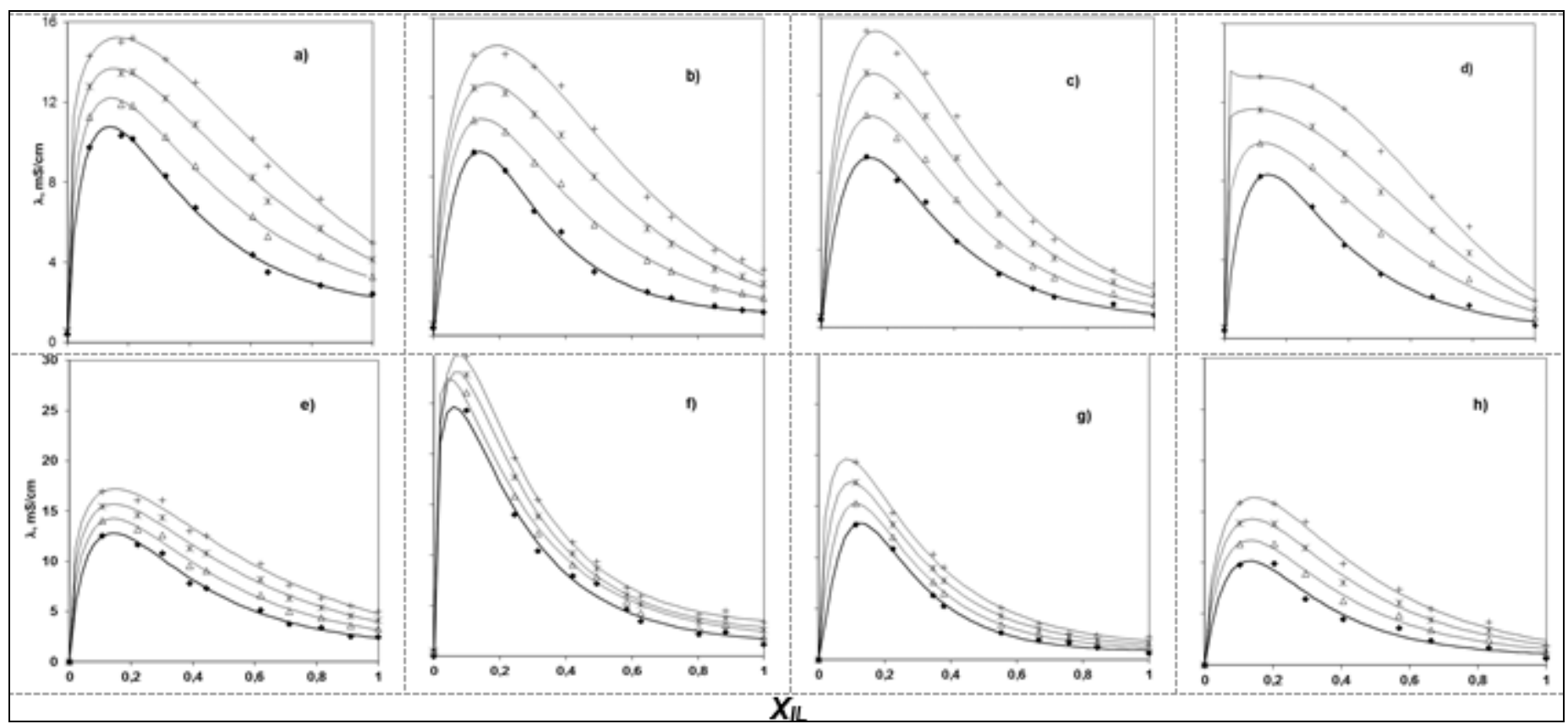

Fig. 2. Electrical conductivities $v s$. mole fraction of ionic liquid in binary mixtures ofa) [Bmim][BF4]+DMSO; b) [Bmim][PF6]+DMSO; c) $[\mathrm{Bmmim}][\mathrm{BF} 4]+\mathrm{DMSO}$; $)[\mathrm{Hmim}][\mathrm{BF} 4]+\mathrm{DMSO}$; $)[\mathrm{Bmim}][\mathrm{BF} 4]+\mathrm{ACN}$; $)[\mathrm{Bmim}][\mathrm{PF} 6]+\mathrm{ACN}$; g) $[\mathrm{Bmmim}][\mathrm{BF} 4]+\mathrm{ACN}$;

h) $[\mathrm{Hmim}][\mathrm{BF} 4]+\mathrm{ACN}$ at different temperatures: $\bullet, 298.15 \mathrm{~K} ; \Delta, 308.15 \mathrm{~K} ; * 318.15 \mathrm{~K}$ and +,328.15 K;

The solid lines represent the fit of these data to eq. Casteel-Amis

To understand the influence of cation and anion on extreme conductivity in the binary mixtures we present the dependence of maximum conductivity, $\lambda_{\max }$, on temperature (Figures $3 \mathrm{a}$ and $4 \mathrm{a}$ ) and the dependence of conductivity on mole fraction (Figures $3 b$ and $4 b$ ). As it can be seen from Fig. $3 a$, the values for $\lambda_{\max }$ follow the same regularity as in the neat ILs: $[\mathrm{Bmim}][\mathrm{BF} 4]>[\mathrm{Bmim}][\mathrm{PF} 6]>[\mathrm{Bmmim}][\mathrm{BF} 4]>[\mathrm{Hmim}][\mathrm{BF} 4]$ at lower temperatures, while at $\mathrm{T}=328.15 \mathrm{~K}$ the system $[\mathrm{Bmmim}][\mathrm{BF} 4]+\mathrm{DMSO}$ presents the highest $\lambda_{\max }$, even greater than for the $[\mathrm{Bmim}][\mathrm{BF} 4]+\mathrm{DMSO}$ system. Also, we can observe a similar order in $\lambda$ variation at constant temperature (Fig. 3b), especially at lower mole fraction $\left(X_{I L}<\right.$ $0.5)$. For the systems with acetonitrile, the highest $\lambda_{\max }$ are observed for [Bmim][PF6]+ACN system, followed by $[\mathrm{Bmmim}][\mathrm{BF} 4]+\mathrm{ACN},[\mathrm{Bmim}][\mathrm{BF} 4]+\mathrm{ACN}$ and $[\mathrm{Hmim}][\mathrm{BF} 4]+\mathrm{ACN}$ systems (fig. 4a), while at higher compositions $\left(X_{K L}>0.5\right)$ the order of variation of conductivity is almost similar as in neat ILs. One reason for this observed inversion of the expected order could be the lack of enough experimental data in the diluted region $\left(0<X_{I L}<0.15\right)$.

Rev. Chim. $71 \bullet$ no. $2 \bullet 2020 \bullet$ https://revistadechimie.ro

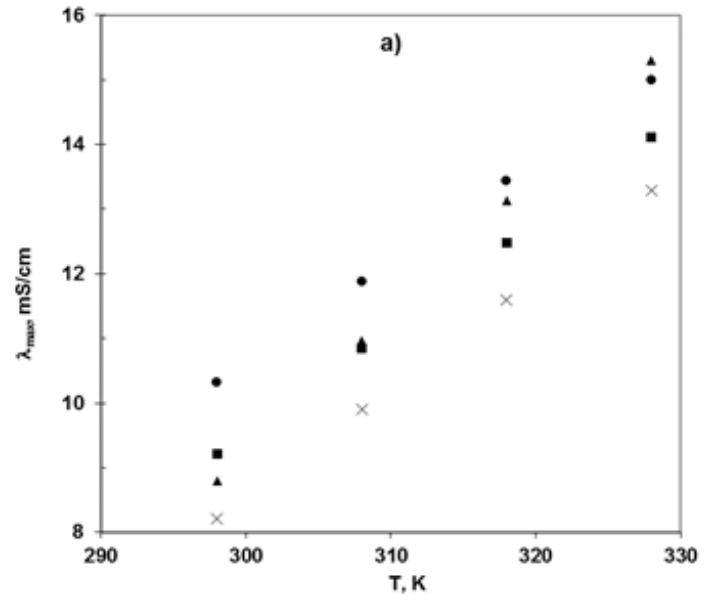

Rev. Chim. $71 \diamond$ no. $2 \diamond 2020 \diamond$ https://revistadechimie.ro

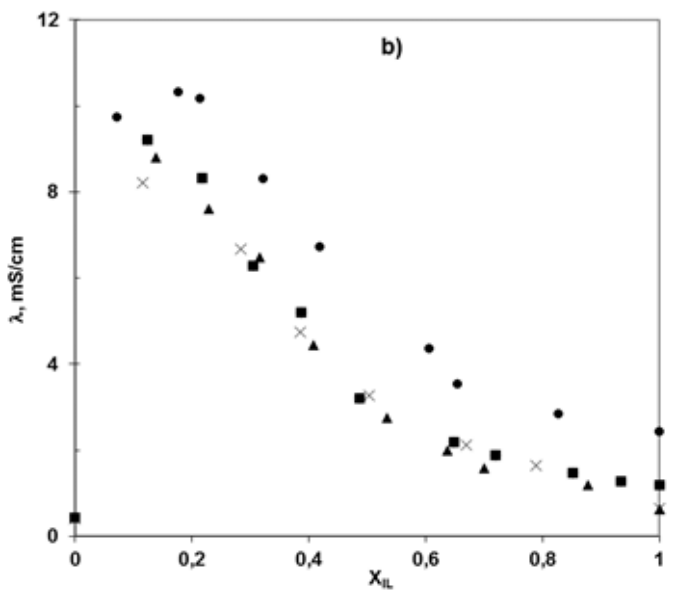

398 
Fig. 3 Dependences of (a) maximum electrical conductivity, $\lambda_{\max }$, on temperature and of (b) electrical conductivity at $298.15 \mathrm{~K}$ on ionic liquid mole fraction for the mixtures with DMSO:•, [Bmim][BF4]; $\mathbf{a},[\mathrm{Bmim}][\mathrm{PF} 6]$;

$\boldsymbol{\Delta},[\mathrm{Bmmim}][\mathrm{BF} 4] ; \times,[\mathrm{Hmim}][\mathrm{BF} 4]$
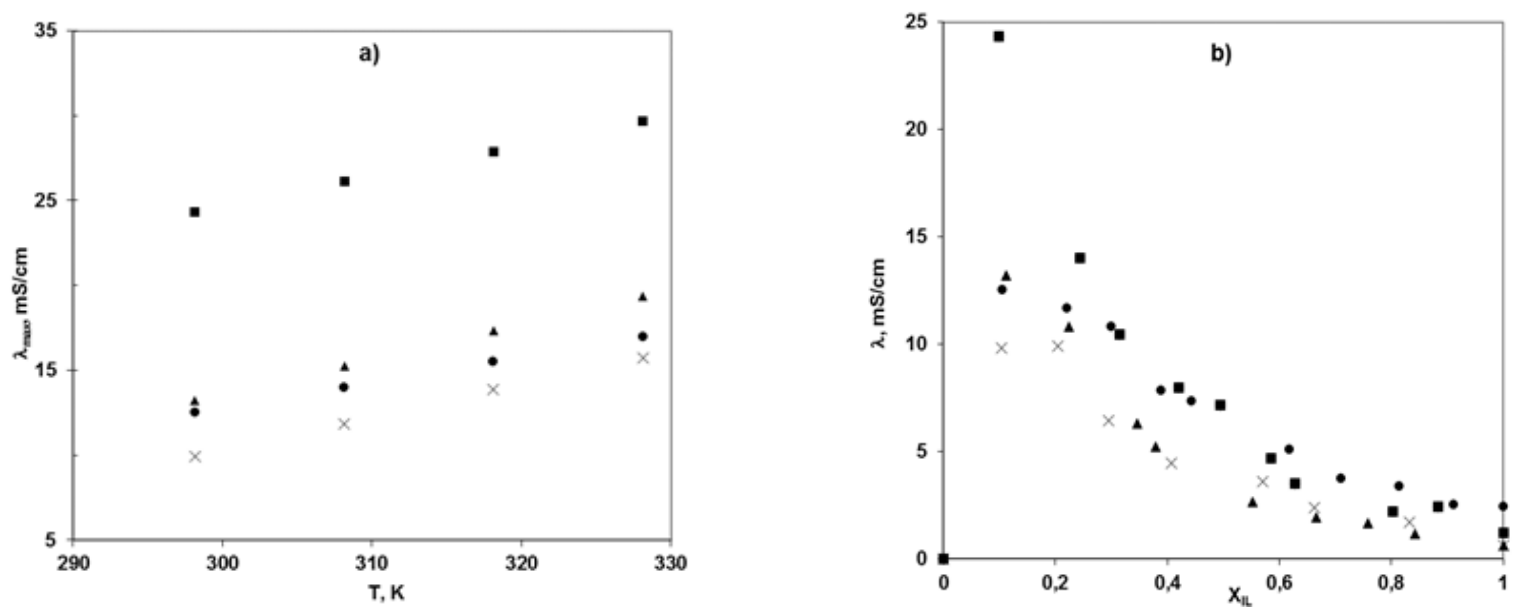

Fig. 4 Dependences of (a) maximum electrical conductivity, $\lambda_{\max }$, on temperature and of (b) electrical conductivity at $298.15 \mathrm{~K}$ on ionic liquid mole fraction for the mixtures with $\mathrm{ACN}$ : •, $[\mathrm{Bmim}][\mathrm{BF} 4] ; \mathbf{a},[\mathrm{Bmim}][\mathrm{PF} 6] ; \boldsymbol{\Delta},[\mathrm{Bmmim}][\mathrm{BF} 4] ; \times,[\mathrm{Hmim}][\mathrm{BF} 4]$

According to Canongia Lopes et al. [34], most small dipolar solvents dissolve the polar network of ILs' and will be able to interact directly with the ions that compose it. The difference between the systems with DMSO and ACN, both solvents having high dipole moments, can be explained by their specific structural features. On one hand, these solvents have different molar volumes $\left(73,3 \mathrm{~cm}^{3} \cdot \mathrm{mol}^{-1}\right.$ for DMSO and $52.9 \mathrm{~cm}^{3} \cdot \mathrm{mol}^{-1}$ for ACN at $\left.298.15 \mathrm{~K}\right)$, on the other hand, the DMSO molecule has a larger nonpolar moiety (weakly polar group $\mathrm{S}=\mathrm{O}$ anchored by two methyl groups). Therefore, the DMSO molecule will be only partially dissolved into the nonpolar regions of the ionic liquid [38]; molecules of acetonitrile could accommodate better in the interstitial space of ionic liquids, having a larger distribution in the nanosegregated parts of the ionic liquid. In conclusion, ACN molecules can better "solubilize" ionic liquids than DMSO. This trend of variation of electrical conductivities in the systems of imidazolium-based ionic liquids with ACN was observed by other authors, too $[9,12]$.

An useful tool is the relation between transport properties, i.e. the Walden rule [41], which connects ionic conductivity with dynamic viscosity. From the conductivity data and densities and viscosities data previously reported by us [19-21,42] we calculated the molar conductivities, $\Lambda$, with the usual equations:

$$
\begin{aligned}
& \text { for neat ILs: } \Lambda=\lambda \cdot M / \rho \\
& \text { for mixtures: } \Lambda=\lambda / c
\end{aligned}
$$

where $M$ is the molar mass $\left(\mathrm{kg} \cdot \mathrm{mol}^{-1}\right)$ of the ILs, $c$ is the molar concentration of the mixtures.

Rev. Chim. $\bullet 1 \bullet$ no. $2 \diamond 2020 \diamond$ https://revistadechimie.ro

Afterwards, we calculated the Walden product:

$$
\Lambda \cdot \eta=\text { const }=C
$$

We chose for eq. (6) the logarithmic form:

$$
\lg \Lambda=\lg (1 / \eta)+\lg C
$$

which relates fluidity or inverse viscosity $(1 / \eta)$ with molar conductivity (Walden plot).

In literature the reciprocal poise $\left(\mathrm{P}^{-1}\right)$ is used as a unit for fluidity, while $\mathrm{S} \cdot \mathrm{cm}^{2} \cdot \mathrm{mol}^{-1}$ is used for molar conductivity. This Walden plot serves as a reliable means for quantification of ion association in neat ILs and includes the "ideal" Walden line, which represents the Walden plot for $0.01 \mathrm{~mol} \cdot \mathrm{dm}^{-3} \mathrm{KCl}$ aqueous solution, known to be fully dissociated and having ions of equal mobility [34,43]. For such ideal dilute aqueous $\mathrm{KCl}$ solution no interaction occurs among the constituent ions. This implies that molar conductivity and viscosity exhibit a perfectly inverse temperature dependence [44]. The deviation from ideal $\mathrm{KCl}$ line is indicative of the existence of ion pairs or ionic aggregates with less conductivity 
than that predicted by the Walden rule. Deviation from the ideal line is commonly observed for most ILs and their mixture [39].

Figure 5 shows the Walden plots for the studied systems with ILs at temperatures varying from 298.15 to $328.15 \mathrm{~K}$. According to Angell et al. [43], for ionic liquids the most favorable systems will have their ambient-temperature values located in the top right-hand corner of the diagram (they include data for systems with fluidities that vary by more than 8 orders of magnitude). Our data are below the "ideal" $\mathrm{KCl}$ line, similar to what other authors have reported [45,46]. In view of the studies reported by Angell et al. [39], we can conclude that since the neat based-imidazolium ionic liquids lie within an order of magnitude below the ideal line, they should be classified as "good" ionic liquids (Fig. 5a). From the Fig. $5 \mathrm{~b}$ ) we can see that Walden plots for the mixtures of [Bmim][BF4] with DMSO and ACN, respectively, are both below the ideal line and, in particular, the data calculated for IL mole fraction corresponding to a maximum of electrical conductivity are placed further to the right in the diagram. This indicates that the binary systems can be considered "better" ionic systems than the pure ones at those "special compositions". Therefore, we could remark the superiority of ILs-ACN/DMSO binary systems for practical purposes.

\section{Computed quantum chemical parameters}

Johansson et al. [23] confirmed that electrical conductivity is inversely proportional to the ion volumes and affected by the reduced masses of the ion pairs. To elucidate the influence of microscopic structure on macroscopic transport properties of the imidazolium-based ILs, we have performed calculations on pure [Bmim][BF4], [Hmim][BF4], $[\mathrm{Bmim}][\mathrm{PF} 6]$ and $[\mathrm{Bmmim}][\mathrm{BF} 4]$ ionic liquids. The geometry of ionic pairs was optimized by energy minimization, and the stable conformers were identified. The obtained IL optimized structures are illustrated in Figure 6, together with their $2 \mathrm{D}$ representations. Selectivity parameters involved in chemical reactivity such as HOMO (the highest occupied molecular orbital) and LUMO (the lowest unoccupied molecular orbital) atomic distribution and their energy diagram were predicted and used to calculate other related properties such as: HOMO -LUMO energy gap ( $\Delta E)$, electron affinity $(E)$, ionization potential $(I)$, electronegativity $(\chi)$, chemical hardness $(\eta)$, global softness $(\sigma)$, chemical potential $(\mu)$, global electrophilicity index $(\omega)$, according to Koopmans' theorem [47,48]. Their values are listed in Table 4, along with molecular volume, dipole moment and polarizability.
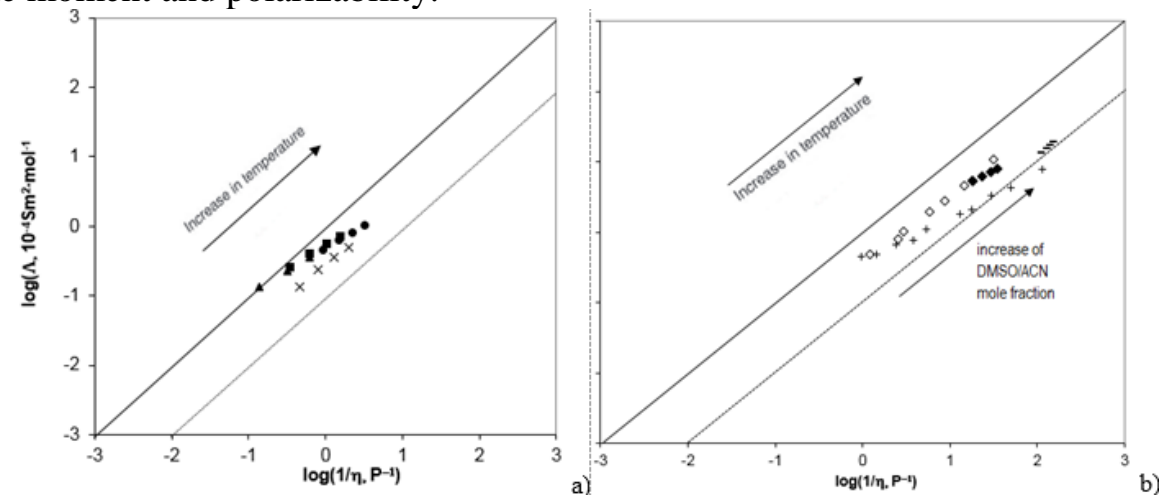

Fig. 5. Walden plot for a) neat ILs: •, [Bmim][BF4], $\mathbf{a},[\mathrm{Bmim}][\mathrm{PF} 6], \times,[\mathrm{Hmim}][\mathrm{BF} 4]$,

$\boldsymbol{\Delta},[\mathrm{Bmmim}][\mathrm{BF} 4]$; b) binary systems of $[\mathrm{Bmim}][\mathrm{BF} 4]+\mathrm{DMSO}(\diamond)$ and $[\mathrm{Bmim}][\mathrm{BF} 4]+\mathrm{ACN}(+)$ calculated in the whole composition range at $\mathrm{T}=298.15 \mathrm{~K}$ and of $[\mathrm{Bmim}][\mathrm{BF} 4]+\mathrm{DMSO}(\bullet)$ and $[\mathrm{Bmim}][\mathrm{BF} 4]+\mathrm{ACN}(-)$ calculated at those $\mathrm{X}_{\mathrm{IL}}$ where we have maximum of electrical conductivity; the solid black line represents the ideal $\mathrm{KCl}$ line $\left(0.01 \mathrm{~mol} \cdot \mathrm{L}^{-1}\right)$.

Rev. Chim. $71 \bullet$ no. $2 \bullet 2020 \bullet$ https://revistadechimie.ro

Table 4

CALCULATED QUANTUM CHEMICAL PARAMETERS OF THE STUDIED IONIC LIQUIDS 


\begin{tabular}{|c|c|c|c|c|}
\hline Quantum parameters & [Bmim] [BF4] & {$[\mathrm{Bmim}][\mathrm{PF} 6]$} & [Bmmim] $[\mathrm{BF} 4]$ & [Hmim] [BF4] \\
\hline$E_{\text {HOMO }}(\mathrm{eV})$ & -8.23 & -8.46 & -7.70 & -8.21 \\
\hline$E_{\text {LUMO }}(\mathrm{eV})$ & -1.32 & -1.63 & -1.10 & -1.34 \\
\hline$\Delta E\left(E_{\text {HONO }}-E_{\text {LUNO }}\right)(\mathrm{eV})$ & 6.91 & 6.83 & 6.60 & 6.87 \\
\hline$T=-E_{\text {HOWO }}(\mathrm{eV})$ & 8.23 & 8.46 & 7.70 & 8.21 \\
\hline$A=-E_{\text {LENO }}(\mathrm{eV})$ & 1.32 & 1.63 & 1.10 & 1.34 \\
\hline$\chi=(I+A) / 2(\mathrm{eV})$ & 4.775 & 5.045 & 4.400 & 4.775 \\
\hline$\eta=(I-A) / 2(\mathrm{eV})$ & 3.455 & 3.415 & 3.300 & 3.435 \\
\hline$\sigma=1 / \eta$ & 0.289 & 0.293 & 0.303 & 0.291 \\
\hline$\mu=\left(E_{\text {HOMO }}+E_{\text {LEMO }}\right) / 2$ & -4.78 & -5.05 & -4.40 & -4.76 \\
\hline$\omega=\mu \mu^{2} / 2 \eta$ & 39.39 & 43.46 & 31.95 & 39.16 \\
\hline Dipole moment (Debye) & 13.27 & 15.00 & 12.41 & 12.58 \\
\hline $\begin{array}{l}\text { Polarizability } \\
\left(10^{-30} \cdot \mathrm{m}^{3}\right)\end{array}$ & 57.92 & 59.62 & 59.46 & 60.93 \\
\hline Volume $\left(A^{3}\right)$ & 224.04 & 244.80 & 242.21 & 264.12 \\
\hline $\begin{array}{l}\text { Energy B97X-V/6- } \\
311+G(2 d f, 2 p)\end{array}$ & -847.89 & -1364.02 & -887.20 & -926.51 \\
\hline
\end{tabular}

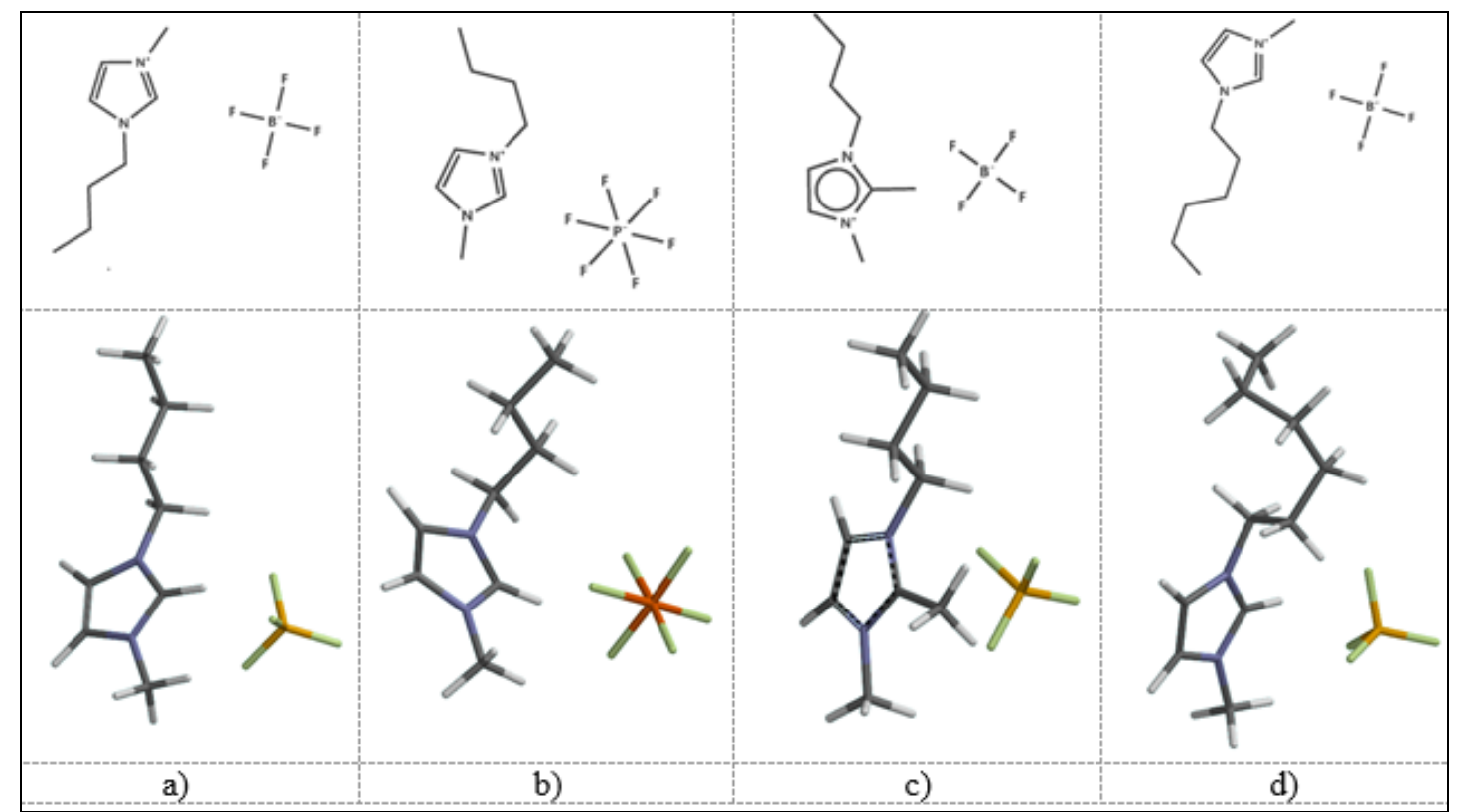

Fig. 6. 2D structures and 3D optimized geometries for a) [Bmim][BF4]; b) [Bmim][PF6], c) [Bmmim][BF4] and d) [Hmim][BF4] ionic liquids, B3LYP/6-31++G(d,p)

The results from Table 4 suggest that among the ionic liquids studied, [Bmim][BF4] is the most stable, having the greatest energy gap between frontier molecular orbitals (the biggest $\Delta \mathrm{E}$ values). The introduction of a second methyl group in the imidazolium ring leads to an increase in reactivity (the smallest HOMO - LUMO energy gap). The molecular volumes increase with the increase in alkyl side chain length on the aromatic imidazolium ring: [Bmim] [BF4] < $[\mathrm{Bmmim}][\mathrm{BF} 4]<[\mathrm{Bmim}][\mathrm{PF} 6]<[\mathrm{Hmim}][\mathrm{BF} 4]$, which is almost the reversed order for the observed conductivity.

Rev. Chim. $71 \bullet$ no. $2 \diamond 2020 \bullet$ https://revistadechimie.ro 


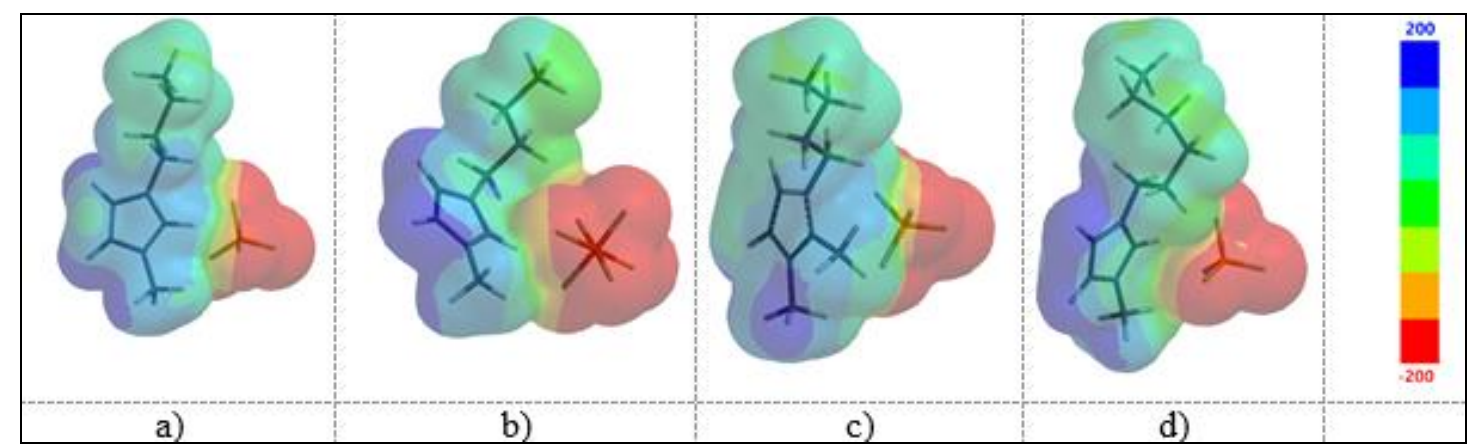

Fig. 7. Molecular electrostatic potential map (MEP) for a) [Bmim][BF4]; b) [Bmim][PF6],

c) $[\mathrm{Bmmim}][\mathrm{BF} 4]$ and d) $[\mathrm{Hmim}][\mathrm{BF} 4]$ ionic pairs at the B3LYP/6-31 + G(d,p) level of theory; the lowest electrostatic potential energy is represented in red color, and the highest, in blue

From the charge distribution calculations reflected by the electronic potential graphical representation (MEP) (fig. 7), it appears that the highly localized negative charge on the anions can explain relatively strong cation-anion coulombic interactions in the IL ion pairs and can predict interactions with the polar molecules like DMSO or ACN.

\section{Conclusions}

We measured electrical conductivity of [Bmim][BF4], [Hmim][BF4], [Bmim][PF6] and [Bmmim][BF4] ionic liquids and their binary mixtures with ACN and DMSO, respectively, at temperatures between $298.15 \mathrm{~K}$ and $328.15 \mathrm{~K}$. An universal property of binary ionic liquid-organic solvent mixtures is the presence of maximum on the electrical conductivity dependence on ionic liquid mole fraction. Notably, all binary systems exhibit conductivity maximum between $X_{I L}=0.1$ and 0.2 and these values for $\lambda_{\max }$ are smaller for binary systems with DMSO than with ACN. We have discussed the factors affecting the interactions between ILs and organic solvents such as the structure and molecular volume of the molecular solutes. The Walden plots obtained for the neat ILs/mixtures indicate that these systems can be classified as "good" ionic systems, especially the mixtures with maximum in electrical conductivity.

Acknowledgement. This work was supported by a grant of Ministry of Research and Innovation, CNCS - UEFISCDI, project number PN-III-P4-IDPCE-2016-0629, within PNCDI III”.

\section{References}

1.MACFARLANE, D. R., TACHIKAWA, N., FORSYTH, M., PRINGLE, J. M., HOWLETT, P. C., ELLIOTT, G. D., DAVIS, J. H., WATANABE, M., SIMON, P., ANGELL, C. A., Energy Environ. Sci., 7, no. 1, 2014, p. 232

2.WANG, S., WANG, X., Angew. Chem. Int. Ed., 55, no.7, 2016, p.2308

3.PÂRVULESCU, V. I., HARDACRE, C., Chem. Rev., 107, no. 6, 2007, p. 2615

4.OPREA, O., CIOCIRLAN, O., BADANOIU, A., VASILE, E., Centr. Eur. J. Chem., 12, no. 7, 2014, p.749

5.FU, Y., CUI, X., ZHANG, Y., FENG, T., HE, J., ZHANG, X., CHENG, Q., J. Chem. Eng. Data, 63, no. 5, 2018, p. 1180

6.CHABAN, V.V., VOROSHYLOVA, I.V., KALUGIN, O.N., PREZHDO, O.V., J. Phys. Chem. B, 116, no. 26, 2012, p. 7719

7.ZHANG, Q., LIU, D., LI, Q., ZHANG, X., WEI, Y., J. Chem. Eng. Data, 63, no. 5, 2018, p. 1256

8.ZHU, A., WANG, J., HAN, L., FAN, M., Chem. Eng. J., 147, no. 1, 2009, p. 27

9.KALUGIN, O. N., VOROSHYLOVA, I. V., RIABCHUNOVA, A. V., LUKINOVA, E. V., CHABAN, V. V., Electrochim. Acta, 105, 2013, p. 188

10.STOPPA, A., HUNGER, J., BUCHNER, R., J. Chem. Eng. Data, 54, 2009, p. 472

11.LI, W., ZHANG, Z., HAN, B., HU, S., XIE, Y., YANG, G., J. Phys. Chem. B, 111, no. 23, 2007, p. 6452

12.BHAT, M. A., DUTTA, C. K., RATHER, G. M., J. Mol. Liq., 181, 2013, p.142

13.CONWAY, B., UITVLUGT, C., MARONCELLI, M., J. Phys. Chem. B, 122, no. 29, 2018, p. 7385

14.ZHANG, Y., HE, H., ZHANG, S., FAN, M., ACS Omega, 3, no. 2, 2018, p. 1823

15.JACOB, S. W.; JACK, C. Dimethyl Sulfoxide (DMSO) in Trauma and Disease; CRC Press, 2015

16.OMOTA, L. M., IULIAN, O., OMOTA, F., CIOCIRLAN, O., Rev. Roum. Chim, 54, nr. 1, 2009, p.63.

17.CIOCIRLAN, O., IULIAN, O., Rev. Chim.,, 59, no. 1, 2008, p. 45

18.CIOCIRLAN, O., IULIAN, O., CROITORU, O., Rev. Chim., 61, no. 8, 2010, p.721

19.CIOCIRLAN, O., IULIAN, O., J. Chem. Eng. Data, 57, no. 11, 2012, p. 3142

20.CIOCIRLAN, O., CROITORU, O., IULIAN, O., J. Chem. Eng. Data, 56, no. 4, 2011, p. 1526

21.CIOCIRLAN, O., J. Chem. Eng. Data, 63, no. 11, 2018, p. 4205

22.CROITORU, O., CIOCIRLAN, O., IULIAN, O., UPB Sci. Bull. Series B, 73, no. 2, 2011, p. 85

23.NILSSON-HALLÉN, J., AHLSTRÖM, B., MARCZEWSKI, M., JOHANSSON, P., Front. Chem., 7, 2019,126

24.BECKE, A.D., J. Chem. Phys., 98, 1993, p. 5648

Rev. Chim. 71 no. 2 2020 https://revistadechimie.ro

Rev. Chim. $71 \downarrow$ no. 2 \2020 https://revistadechimie.ro 
25.HEHRE, W.J., A Guide to Molecular Mechanics and Quantum Chemical Calculations, Wavefunction, Inc. Irvine, CA, 2003.

26.SHAO, Y., GAN, Z., EPIFANOVSKY, E., GILBERT, A. T., WORMIT, M., KUSSMANN, J., ... GHOSH, D., Molec. Phys., 113, no. 2, 2015, p. 184

27.YU, Y. H., SORIANO, A. N., LI, M. H., Thermochim. Acta, 482, no. 1-2, 2009, p. 42

28.STOPPA, A., ZECH, O., KUNZ, W., BUCHNER, R., J. Chem. Eng. Data, 55, no. 5, 2010, p. 1768

29.NING, H., HOU, M., MEI, Q., LIU, Y., YANG, D., HAN, B., Sci. China Chem. 55, no. 8, 2012, p. 1509

30.ANDRIYKO, Y. O., REISCHL, W., NAUER, G. E., J. Chem. Eng. Data, 54, no. 3, 2009, p. 855

31.RILO, E., VILA, J., GARCÍA, M., VARELA, L. M., CABEZA, O., J. Chem. Eng. Data, 55, no. 11, 2010, p. 5156

32.HUNT, P.A., J. Phys. Chem. B, 111, 2007, p. 4844

33.ZHANG, Q., LIU, D., LI, Q., ZHANG, X., WEI, Y., LANG, X., J. Mol. Liq., 268, 2018, p.770

34.PANDIT, S. A., RATHER, M. A., BHAT, S. A., RATHER, G. M., BHAT, M. A., J. Solution Chem., 45, no. 12, 2016, p. 1641

35.CANONGIA LOPES, J. N., PÁDUA, A. A, J. Phys. Chem. B 110, 2006, p. 3330

36.WANG, Y. T., VOTH, G. A., J. Am. Chem. Soc. 2005, 127, no. 35,2005, p. 12192

37.AFANDAK, A., ESLAMI, H., J. Phys. Chem. B, 121, no. 32, 2017, p.7699

38.CANONGIA LOPES, J. N., COSTA GOMES, M. F., HUSSON, P., PÁDUA, A. A., REBELO, L. P. N., SARRAUTE, S., TARIQ, M., J. Phys. Chem. B, 115, no. 19, 2011, p. 6088

39.PAPOVIĆ, S., GADŽURIĆ, S., BEŠTER-ROGAČ, M., JOVIĆ, B., VRANEŠ, M., J. Chem. Thermodyn, 116, 2018, p. 330

40.CASTEEL, J.F., AMIS, E.S., J. Chem. Eng. Data, 17, 1972, p. 55

41.WALDEN, P., Z. Phys. Chem. 55, 1906, p. 207

42.CIOCIRLAN, O., J. Chem. Eng. Data, 63, no. 11, 2018, p. 4205

43XU, W., COOPER E. I., ANGELL, C. A., J. Phys. Chem. B, 107, no. 25, 2003, p. 6170

44.UENO, K., TOKUDA, H., WATANABE, M., Phys. Chem. Chem. Phys., 12, no. 8, 2010, p.1649

45.MACFARLANE, D. R., FORSYTH, M., IZGORODINA, E. I., ABBOTT, A. P., ANNAT, G., FRASER, K., Phys. Chem. Chem. Phys., 11, no. 25, 2009, p. 4962

46.THAWARKAR, S., KHUPSE, N. D., SHINDE, D. R., KUMAR, A., J. Mol. Liq., 276, 2019, p. 986

47.SASTRI, V.S., PERUMAREDDI, J.R., Corr. Sci., 53, no. 8, 1997, p. 617

48.YANKOVA, R., GENIEVA, S., HALACHEV, N., DIMITROVA, G., J. Molec. Struct., 1106, 2016, p. 82

$\overline{\text { Manuscript received: } 13.08 .2019}$ 
